\title{
Complexity-simplicity: II. Birth order and sex differences'
}

RUSSELL EISENMAK

TEMPLE UNIVERSITY

The preferences of 224 Ss for polygons of varying degrees of complexity were analyzed in terms of $S s^{\prime}$ birth order and sex. Analysis of variance indicated that sex was a highly significant determinant of complexity preference, with $f e-$ males tending to prefer more complexity than males, and, in addition, there was a significant sex $x$ birth order interaction, with first born males preferring more complexity than later born males, but later bom females preferring more complexity than first bom females.

Recent studies of stimulus variability (Fiske \& Maddi, 1961; Munsinger \& Kessen, 1966) have suggested that characteristics of the subject may influence his preferred amount of stimulus variability. Eisenman (in press (a)) found birth order differences in response to asymmetrical, randomly constructed polygons which had been taken from those employed by Vanderplas \& Garvin (1959). First born males preferred more complexity than later born males, but first born females preferred less complexity than later born females. Since that time, unpublished research as well as another study (Eisenman, in press (b)) have suggested that females may tend to prefer greater amounts of complexity in the polygons utilized. The present research was undertaken to see if use of a large sample could replicate and extend previous findings.

Subjects

The Ss were 224 students from six classes at Temple University.

Procedure

The Ss were presented with nine polygons of asymmetrical, randomly constructed shapes taken from Vanderplas \& Garvin (1959). These shapes were mounted on a large cardboard in a 3 by 3 arrangement. There were three polygons from each of the following levels of complexity: 4-, 12-, and 24-points, with complexity defined by the number of points (Attneave, 1957; Attneave \& Arnoult, 1956). Ss were instructed either to rank order the shapes in terms of preference or to choose their three most preferred and three least preferred. No differences were found due to the varying manner in which $\mathrm{Ss}$ were requested to make their cholces. The ranking of polygons from 1 to 9 was abandoned on the grounds that $\mathbf{E}$ was only interested in three most and three least preferred, and Ss were thus faced with a difficult task in trying to place polygons in the 4,5 , and 6 positions. A complexity score was obtained by subtracting the total number of points on the three least preferred polygons from the total number of points on the three most preferred shapes.
Results

Table 1 shows the mean complexity scores for Ss in the present study. A 2 by 2 analysis of variance indicated significance beyond the .01 level for sex, and beyond the .05 level for an interaction of birth order by sex. The female Ss in general tended to have higher complexity scores than male Ss. Among males, first born males preferred more complexity than later born males, but the birth order relationship was reversed for females, with first born females preferring less complexty than later born female Ss. A separate analysis excluding only child Ss from the first born category failed to yield any differences from the above-mentioned analysis in which the dilemma of what to do with only child Ss was resolved by including them in the first born category.

\section{Discussion}

Since preference for complexity has been linked to creativity (Barron, 1963; Taylor \& Eisenman, 1964; Eisenman, unpublished data), it is striking to note the greater complexity scores of females in general, and the birth order by sex interaction as well. Female Ss generally seem more conforming, more moralistic (Eisenman, in press (c)), and otherwise less creative than male Ss, so the present results are somewhat surprising. Perhaps females are more responsive to social influence than males, but do not necessarily lack appreciation of stimulus variability, creativity, etc. With regard to the similarity of later born females and first born males in preferring complexity, it may be first born males recelve an honored position in many families as the eldest male, while first born females are, due to their sex, subjected to more intensive socialization from their parents, thus resulting in a more inhibited person than their less intensely socialized later born sisters. Further speculation on socialization and creativity can be found in Barron (1963).

The results are also relevant for the investigator of variability since first borns tend to be represented to a disproportionate extent on college campuses. It would seem that related studies would do well to

Table 1. Mean complexity scores by birth order and sex

\begin{tabular}{lrc} 
& \multicolumn{2}{c}{ Sex } \\
Birth Order & Moles & Females \\
First born & 41.8 & 47.4 \\
Later born & 35.5 & 51.4
\end{tabular}

Note: A constant of 61 was added to each $S^{\prime \prime} s$ score to eliminate minuses 
analyze data for possible birth order and sex differences. Direct study of children is needed to understand better why birth order and sex seem to be such powerful variables.

\section{References}

Attheave, F. Physical determinants of the judged complexity of shapes. J. exp. Psychol., 1957, 53, 221-227.

Attneave, F., Amoult, M. D. Methodological considerations in the quantitative study of shape and pattern perception. Psychol. Bull., 1956, 53, 452-471.

Barron, F. Creativity and psychological health. Princeton, N. J.: Van Nostrand, 1963.

Eisenman, R. Birth order and sex differences in aesthetic preference for complexity-simplicity. J. gen. Psychol., in press. (a)

Eisenman, R. Birth order, insolence, socialization, intelligence, and complexity-simplicity preferences. J. gen. Psychol., in press. (b)

Eisenman, R. Sex differences in moral judgment. Percept. mot. Skills, in press. (c)

Fiske, D. W., \& Maddi, S. R. (Eds.) Functions of varied experience. Homewood, Ill.: Dorsey, 1961.

Munsinger, H., \& Kessen, W. Stimulus variability and cognitive change. Psychol. Rev., 1966, 73, 164-178.

Taylor, R. E., \& Eisenman, R. Perception and production of complexity by creative art students. J. Psychol., 1964, 57, 239-242.

Vanderplas, J. M., \& Garvin, E. A. The association value of random shapes. J. exp. Psychol., 1959, 57, 147-154.

Note

1. This research was supported by a grant from Temple University. The author is grateful to Joan Rappaport who assisted in data collection and analysis. 